\title{
Biogeography of globally distributed bacteria in temperate and boreal Québec lakes as revealed by tag pyrosequencing of 16S rRNA genes
}

\author{
Matthew T. Cottrell ${ }^{1, *}$, Paul A. del Giorgio ${ }^{2}$, David L. Kirchman ${ }^{1}$ \\ ${ }^{1}$ School of Marine Science and Policy, University of Delaware, Lewes, DE 19958, USA \\ ${ }^{2}$ Département des Sciences Biologiques, Université du Québec à Montréal, Montreal, QC H3C 3P8, Canada
}

\begin{abstract}
Sequence data of 16S rRNA genes reveal that many bacterial taxa are found in all freshwater lakes. However, the global data set is highly weighted toward lakes in temperate regions of North America and northern Europe, and it is unclear whether bacterial communities in other northern latitude environments, such as boreal lakes in North America, differ from those in lower latitudes. This study used pyrosequences of the 16S rRNA gene to examine bacterial diversity in 37 temperate and boreal lakes in Québec, Canada, over the course of a year. Nearly all taxa in the global data set were also found in the Québec lakes, but relative abundances differed. Community structure varied geographically and seasonally for $97 \%$ similar operational taxonomic units (OTUs) but not at lower levels of similarity. Seasonal shifts in community structure were larger in temperate lakes than in boreal lakes, and community structure differed between boreal and temperate lakes in summer but not in winter. The differences in taxonomic composition between temperate and boreal lakes appear to be driven mostly by environmental processes influencing community structure of temperate lakes in summer. Our results provide a baseline for interpreting impacts of climate change in boreal biomes where community structure is driven by environmental factors.
\end{abstract}

KEY WORDS: Bacteria $\cdot$ Boreal $\cdot$ Temperate $\cdot$ Freshwater $\cdot$ Lake $\cdot$ Biogeography

\section{INTRODUCTION}

The biogeographic patterns in aquatic bacterial communities result from processes acting over a broad range of temporal and spatial scales. Bacterial communities inhabiting marine and freshwater systems are clearly different even at the phylum and class level (Glöckner et al. 1999, Barberán \& Casamayor 2010), and bacterial communities appear to vary among various oceanic regions (Pommier et al. 2007, Pontarp et al. 2012). Bacterial richness varies with latitude between ocean basins (Fuhrman et al. 2008). Despite advances in describing the broad distributions of microbes in the oceans, there has been less progress in identifying biogeographic patterns of bacteria in freshwater lakes (Logue \& Lindström

${ }^{*}$ Corresponding author: mattcott@udel.edu
2008). However, the application of next-generation sequencing tools is rapidly advancing knowledge about long-term shifts in bacterial communities in lakes (Logares et al. 2013), community dynamics and association networks (Eiler et al. 2012, Peura et al. 2015), and links between community structure and function (İnceoğlu et al. 2015). Still, previous studies have led to conflicting views of freshwater bacterial communities. Some studies indicate that each lake harbors a unique bacterial community (Yannarell \& Triplett 2005), while others suggest that many lakes harbor the same bacterial taxa (Newton et al. 2011).

Some of the conflicting views about freshwater bacterial communities may result from the sequencing and community fingerprinting methods used by previous studies. Fingerprinting methods can be

(C) The authors 2015. Open Access under Creative Commons by Attribution Licence. Use, distribution and reproduction are unrestricted. Authors and original publication must be credited. 
applied to a large number of samples but recover only the most abundant bacteria (Kan et al. 2006). Sequencing approaches using clone libraries can potentially be used to obtain deep sequencing coverage, but at the expense of examining only a few samples. As a consequence, previous studies of freshwater communities considered mostly abundant microbes (Newton et al. 2011), potentially underestimating alpha diversity. In contrast, pyrosequencing of PCR amplicons and stringent controls of sequencing artifacts (Lee et al. 2012) can be applied to large numbers of samples and achieve a much greater sequencing depth, on the order of $10^{6}$ reads (Caporaso et al. 2012), resulting in alpha diversity values at least 10 -fold greater than previous estimates from traditional approaches (Sogin et al. 2006).

Based on global scale surveys that began in the mid-1990s, Newton and co-authors (2011) generated a list of approximately 80 bacterial taxa, including 21 phyla, that appear to occur worldwide in surface waters of lakes. Coverage of the surveys was global and included lakes on 6 continents, yet the data are highly skewed towards lakes in temperate environments. Half of the surveys were concentrated on temperate lakes in just 12 European countries. Lakes in the temperate regions of New England, the Midwest and the Northwest of the USA dominate the data from North America. Although the data set does include observations from a few boreal lakes in Sweden and Finland, no lakes from boreal environments of North America were surveyed. The surveys also under-sampled lakes in tropical environments, where data on bacteria are sparse (Sarmento 2012).

Watershed processes may impact boreal lakes differently than temperate lakes, potentially leading to divergence between boreal and temperate lake bacterial communities. For example, there are major differences in soil properties, the extent of peatlands and other watershed properties known to influence carbon and nutrient dynamics in lakes (Benoy et al. 2007). Further, there are differences in the degree of terrestrial influence on lake processes. Input of bacteria from rivers (Lindstrom et al. 2006), headwater streams and soils have been shown to affect lake bacterial communities (Crump et al. 2007, 2012, Kulichevskaya et al. 2011). In this regard, hydrological networks have very different conformations in boreal and temperate landscapes (Woo et al. 2008, Buffam et al. 2011), and these different network architectures may influence the patterns in bacterial communities across lakes (Logue \& Lindström 2008, Ruiz-González et al. 2015a). In spite of the many known differences in watershed and lake chemistry, it is not clear to what extent bacterial community structure differs between temperate and boreal lakes.

In addition to exploring issues in microbial limnology, data from freshwater lakes may help address general questions about the factors shaping bacterial communities and biogeography in natural environments (Hanson et al. 2012). Many lakes are directly connected via the surface or groundwater networks, increasing dispersal and connectivity, and leading to differences in community structure due to mass effects rather than to environmental factors (RuizGonzález et al. 2015a). Further, DNA fingerprinting data indicate that differences among bacterial communities increase with increasing geographic distance separating high mountain lakes (Reche et al. 2005), temperate lakes of Wisconsin, USA (Jones et al. 2012) and lakes in Patagonia (Schiaffino et al. 2011). Data from boreal lakes and other undersampled lakes would be important additions to discussions about the importance of geographic versus environmental processes in shaping biological communities (Chase \& Myers 2011), as well as to the understanding of this crucial component of freshwater ecosystems.

In this study, we first examined the biogeographic patterns of bacterial taxonomic composition in lakes located in 3 distinct regions of Québec, Canada (Laurentian and Appalachian in the south, and northern boreal), and we further assessed whether the biogeographic patterns have a seasonal component. We then used phylogenetic analysis to compare the bacterial communities in these Québec lakes to a global data set of freshwater bacteria (Newton et al. 2011). Our expectation was that lakes in these regions might differ to most of those in the global database as the result of various climatic, geological and topographical influences. Our study used 454 pyrosequencing of 16S rRNA genes, which allowed us to assess the phylogenetic diversity of bacterial communities in a larger number and diversity of boreal and temperate lakes than has been done previously using more limited approaches.

\section{MATERIALS AND METHODS}

\section{Sampling}

We sampled lakes in 3 main regions. The Eastmain River region of boreal Québec $\left(52^{\circ} 14^{\prime} \mathrm{N}, 75^{\circ} \mathrm{W}\right)$ contains an extensive freshwater network covering over $20 \%$ of the landscape in addition to peat bogs, which 
cover an additional $20 \%$ of the area. The region is composed of a mature evergreen forest dominated by black spruce Picea mariana. The 2 temperate regions are distinct in terms of geology, topography, and soils but are close geographically $(<200 \mathrm{~km})$. The Laurentian region is located in the Canadian Shield, north of Montreal $\left(45^{\circ} 59^{\prime} \mathrm{N}, 74^{\circ} 01^{\prime} \mathrm{W}\right)$, dominated by granitic bedrock and mostly covered by mixed forest $(>95 \%)$. The Eastern Townships region is located south of Montreal $\left(45^{\circ} 24^{\prime} \mathrm{N}, 72^{\circ} 12^{\prime} \mathrm{W}\right)$ in the St Lawrence Lowlands, which is dominated by sedimentary geology that results in a higher average $\mathrm{pH}$ and alkalinity in these lakes (Prairie et al. 2002).

A total of 37 lakes were sampled, 12 in the boreal region and 21 in the southern temperate regions, 1 to 5 times each over the course of a year. At each sampling location, we measured the Secchi disk depth and a vertical profile of temperature, $\mathrm{O}_{2}$ and conductivity, using a YSI 600 XLM-M probe. Water samples were collected at $1 \mathrm{~m}$ below the surface, using a peristaltic pump, at the deepest spot of the lakes. The water was placed into 181 carboys. During the icecover period, sampling was carried out through a hole made through the ice. In all cases, the samples were processed in the laboratory less than 4 to $6 \mathrm{~h}$ after collection.

\section{Nucleic acid extractions and next-generation sequencing}

Lake water samples were pre-filtered through $1 \mu \mathrm{m}$ nominal pore size glass fiber filters (GE Water and Process Technologies) to remove organisms larger than bacteria and thus avoid amplifying chloroplast genes during the PCR step. Bacteria were then collected from the free-living bacterial size fraction by filtration onto $0.2 \mu \mathrm{m}$ pore size Durapore (Millipore) filters. Total nucleic acids were extracted using a cetyl trimethylammonium bromide (CTAB) extraction protocol (Dempster et al. 1999).

High-throughput sequencing of the V1-V3 region of the 16S rRNA gene was performed using a Roche 454 instrument with titanium chemistry by the Research and Testing Laboratory (www.researchandtesting. com). Sequencing was done with primers 28F (GAG TTT GAT CNT GGC TCA G) and 519R (GTN TTA CNG CGG CKG CTG). Primers contained previously described barcodes to bio-informatically separate samples after sequencing (Hamady et al. 2008). The PCR conditions were $95^{\circ} \mathrm{C}$ for $5 \mathrm{~min}, 30$ cycles of $95^{\circ} \mathrm{C}$ for $30 \mathrm{~s}, 57^{\circ} \mathrm{C}$ for $30 \mathrm{~s}, 72^{\circ} \mathrm{C}$ for $1 \mathrm{~min}$ and finally $72^{\circ} \mathrm{C}$ for $7 \mathrm{~min}$. Roche Taq polymerase was used.

\section{Sequence analysis}

Low-quality sequences, sequence noise, primers and chimeric sequences were removed using tools in the Quantitative Insights Into Microbial Ecology (QIIME) package v.1.7 (qiime.org) (Caporaso et al. 2010). Sequences were filtered for read quality using a minimum score of 25, allowing no ambiguous bases and no mismatches in the primers. Sequence denoising was done by flowgram clustering (Quince et al. 2011) using the denoiser software (Reeder \& Knight 2010). Sample sizes were normalized to 500 sequences from each lake sample by random sampling. Sequences sharing $\geq 97 \%$ sequence similarity were assigned to operational taxonomic units (OTUs) using the uclust algorithm with the optimal_uclust and user_sort options (Edgar 2010). Chimeric OTUs were removed using ChimeraSlayer (Haas et al. 2011). A representative set of OTU sequences was compiled from the uclust seed sequences (Caporaso et al. 2010).

Taxonomic assignments were made using BLAST (Altschul et al. 1990) with an E value cutoff of 0.001 and a reference database produced by merging the GreenGenes database (http://greengenes.lbl.gov/ Download/Sequence_Data/Fasta_data_files/slice_28f _519R_gg_norm_tax.fasta.gz; accessed 23 December 2011) (DeSantis et al. 2006) and the freshwater lake bacterial database reported by Newton et al. (2011). The merged data set was trimmed to include only the $28 \mathrm{~F}-519 \mathrm{R}$ region of the $16 \mathrm{~S}$ rRNA gene, as suggested by Werner et al. (2012). Trimming was done with the ARB software package (Ludwig et al. 2004). Redundant sequences from the GreenGenes database were identified using the QIIME pick otus.py function with the uclust_ref option (Edgar 2010) and reassigned a taxonomic assignment matching the one appearing in the freshwater database. Relative abundances of taxonomic groups were calculated as the number of sequencing reads assigned to the group divided by the total number of sequences.

Similarity between lakes in the boreal, Laurentian and Eastern Townships regions was calculated using the sim.groups function of the vegetarian package in $\mathrm{R}$ with the Shannon diversity index (Jost 2007). Environmental controls of bacterial community structure were explored using non-metric multidimensional scaling (NMDS) ordination of community structure. Variance partitioning of factors influencing bacterial community structure was accomplished using partial redundancy analysis using the rda function in the vegan $\mathrm{R}$ package (Oksanen et al. 2015). 
Sequences were deposited in the National Center for Biotechnology Information (NCBI) short-read archive database, accession number PRJNA291036.

\section{Chemical analyses}

Total phosphorus (TP) was measured using the molybdenum-blue method with potassium persulfate digestion (Suzumura 2008). Dissolved organic carbon (DOC) was measured on a total organic carbon (TOC) analyzer (OI Analytical) using a high-temperature persulfate oxidation method (Kaplan 1992). Chlorophyll (chl a) concentrations were measured using GF/F glass fiber filters (Whatman) and ethanol extraction. Pigment concentration was calculated from absorbance measured at $750 \mathrm{~nm}$ and $665 \mathrm{~nm}$ using an UltroSpec 2100 spectrophotometer (Biochrom) (Strickland \& Parsons 1968).

\section{RESULTS}

The pyrosequencing results presented here were obtained from 100 samples collected from 32 lakes over the course of a year. The data set includes 3 spring, 58 summer, 16 fall and 23 winter samples collected from 12 boreal lakes and 20 temperate lakes located in the Laurentian and Eastern Townships regions of Québec (see Table S1 in the Supplement at www.intres.com/articles/suppl/a076p175_supp.pdf).

Environmental conditions were highly variable among the lakes without being extreme (Table 1). For example, $\mathrm{pH}$ averaged 7.1, ranging from 6.1 to 7.9, and water temperature ranged from $0^{\circ} \mathrm{C}$ in winter to $23.3^{\circ} \mathrm{C}$ in summer (Table S2). Concentrations of DOC averaged $6.4 \mathrm{mg} \mathrm{l}^{-1}$, varying 6 -fold from 2.3 to $12.8 \mathrm{mg} \mathrm{l}^{-1}$. Chl a concentration varied more widely than the other measured environmental factors, ranging from 0.1 to $11.7 \mu \mathrm{g} \mathrm{l}^{-1}$, but this variability reflects both cross-lake differences in nutrient concentrations and the strong seasonality in the lakes.

\section{Geographic and seasonal variation of bacterial community structure}

Our study revealed a distinct biogeography of bacterial communities in lakes distributed along this $1200 \mathrm{~km}$ latitudinal gradient, ranging from the boreal region in the north to the temperate region in southern Québec. The dissimilarity in community structure between lakes was significantly positively correlated with the geographic distances between lakes (Mantel's test: $r=0.23, p<0.05$ ) (Fig. S1). For OTUs defined at the $85 \%$ level of similarity, the correlation between community dissimilarity and geographic distance was substantially lower $(\mathrm{r}=0.07, \mathrm{p}<0.05)$. There was no significant correlation when OTUs were defined at a level below $85 \%$ similarity (Fig. S1).

In spite of the significant effect of distance, the biogeography of bacterial communities in Québec lakes appears to be driven mostly by environmental factors. Partial redundancy analysis revealed that $41 \%$ of the variation in community structure across Québec lakes could be explained by environmental factors alone (Fig. S1). In contrast, the amount of variation in community structure explained by geographic distance, and the joint effects of geographic distance and environment that cannot be separated due to collinearity, was only $4 \%$ and $6 \%$, respectively. The total amount of variation explained by environment and geographic distance was approximately $50 \%$ (Fig. S1). This percentage did not change when the number of sequences was varied by rarefaction analysis from 100 to 3500 reads per sample, suggesting that the observed biogeographic patterns are mostly driven by the more abundant taxa in these lakes.

Table 1. Characteristics of the Québec lakes summarized by location and season. Data on the individual lake samples are reported in Table S1 in the Supplement at www.int-res.com/articles/suppl/a076p175_supp.pdf. Bor: boreal; Tem: temperate; S: summer; W: winter; $T$ : temperature; TP: total phosphorous; DOC: dissolved organic carbon; chl a: chlorophyll $a_{i}$ SD: standard deviation; $\mathrm{n}$ : total number of samples, including those collected from lakes sampled more than once; nd: not determined

\begin{tabular}{|c|c|c|c|c|c|c|c|c|c|c|c|c|c|c|}
\hline Location & Season & $\begin{array}{c}T \\
\left({ }^{\circ} \mathrm{C}\right)\end{array}$ & $\mathrm{SD}$ & $\mathrm{pH}$ & $\mathrm{SD}$ & $\begin{array}{c}\text { TP } \\
\left(\mu \mathrm{g} \mathrm{l}^{-1}\right)\end{array}$ & $\mathrm{SD}$ & $\begin{array}{c}\text { DOC } \\
\left(\mathrm{mg} \mathrm{l}^{-1}\right)\end{array}$ & $\mathrm{SD}$ & $\begin{array}{c}\text { Chl a } \\
\left(\mu \mathrm{g} \mathrm{l}^{-1}\right)\end{array}$ & $\mathrm{SD}$ & $\begin{array}{c}\text { DOC:chl a } \\
\text { ratio }\end{array}$ & $\mathrm{SD}$ & $\mathrm{n}$ \\
\hline Bor & $\mathrm{S}$ & 19.4 & 1.7 & 6.7 & 0.4 & 10.8 & 5.8 & 8.2 & 1.6 & 2.6 & 0.6 & 3.1 & 0.7 & 13 \\
\hline Bor & W & 3.1 & 4.2 & 6.7 & 0.3 & nd & nd & 8.5 & 1.4 & nd & nd & nd & nd & 9 \\
\hline Tem & $\mathrm{S}$ & 20.2 & 3.4 & 7.3 & 0.8 & 16.3 & 28.5 & 5.9 & 2.9 & 5.8 & 9.6 & 2.1 & 1.4 & 38 \\
\hline Tem & W & 1.2 & 1.1 & 7.4 & 0.4 & 9.7 & 6.2 & 4.3 & 1.2 & 0.5 & 0.5 & 17.9 & 19.8 & 11 \\
\hline
\end{tabular}


Community structure in boreal and temperate lakes differed between summer and winter. In summer, unweighted pair group method with arithmetic mean (UPGMA) analysis revealed 2 deeply branching clusters that were verified using the analysis of similarity test (ANOSIM: $\mathrm{r}=0.18, \mathrm{p}<0.05$ ), including one cluster of 26 temperate lakes and another cluster made up of 13 boreal lake and 4 temperate lake samples (Fig. 1). The clustering was significant in winter as well (ANOSIM: $\mathrm{r}=0.14, \mathrm{p}<0.05$ ), but the clusters contained a mix of both boreal and temperate lakes, and were not dominated by lakes from one or the other region, as was the case for the summer (Fig. S2).

Although the community structure shifted seasonally between summer and winter in both the temperate and boreal lakes, the seasonal differences in composition were more pronounced in temperate lakes

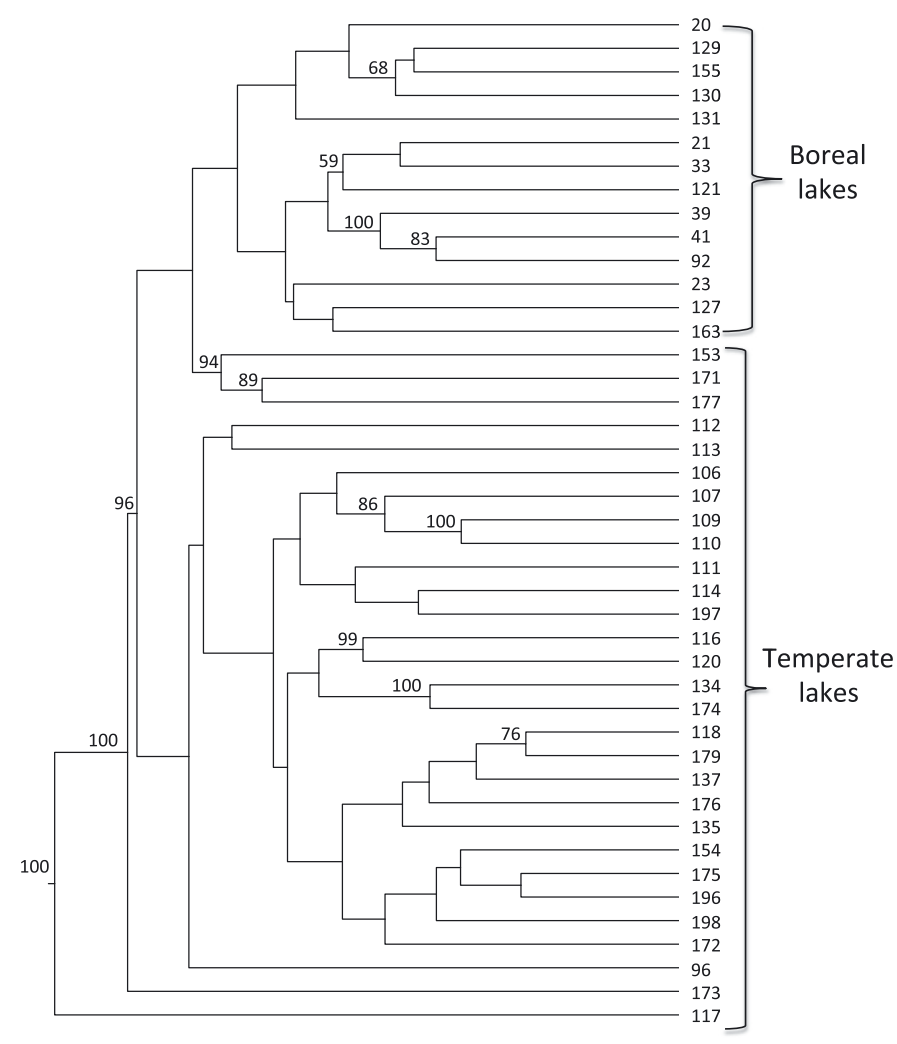

Fig. 1. Unweighted pair group method with arithmetic mean (UPGMA) dendogram of bacterial community structure in boreal and temperate lakes sampled in summer. Temperate lakes include those in the Laurentian and Eastern Township districts of Québec. The distance matrix is based on the abundances of operational taxonomic units (OTUs) defined at $97 \%$ sequence similarity and the Bray-Curtis index. Lake sample ID numbers shown on right. Values at the branch nodes are bootstrap percentages based on 100 trees

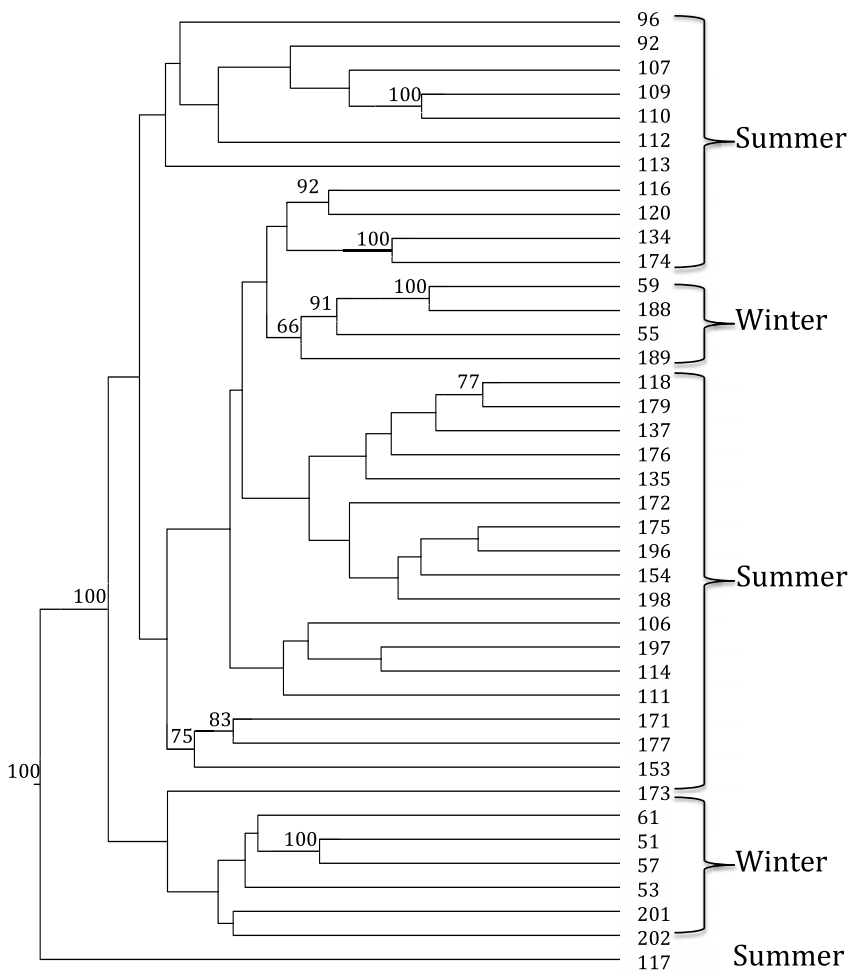

Fig. 2. Unweighted pair group method with arithmetic mean (UPGMA) dendogram of bacterial community structure in temperate lakes sampled in summer and winter. The distance matrix is based on the abundances of OTUs defined at $97 \%$ sequence similarity and the Bray-Curtis index. Lake sample ID numbers shown on right. Values at the branch nodes are bootstrap percentages based on 100 trees

(ANOSIM: $r=0.23, \mathrm{p}<0.05$ ) Fig. 2) than in boreal lakes (ANOSIM: $\mathrm{r}=0.14, \mathrm{p}<0.05$ ). The summer and winter communities in the boreal lakes did not form deeply branching clusters (Fig. S3). This seasonal clustering of lakes detected for $97 \%$ similar OTUs was also evident at the $95 \%$ level of similarity, but not at $90 \%$ similarity or lower, using the Bray Curtis or Unifrac metrics of dissimilarity (data not shown).

We assessed whether geographic or seasonal factors had a larger impact on bacterial community structure in these lakes. Considering all data, community structure differed more because of seasons than because of variation among lakes (ANOVA: $\mathrm{p}<$ 0.05) (Fig. S4). The temperate lakes accounted for the greater impact of seasonal than geographic factors. In the temperate region of Québec, differences in community structure between seasons within lakes $(0.72 \pm 0.09)$ were significantly greater than differences in community structure between lakes in summer $(0.61 \pm 0.15)$ and in winter $(0.58 \pm 0.07)$ (ANOVA: $\mathrm{p}<0.05$ ) (Fig. S4). 


\section{Environmental factors driving seasonal shifts in community structure}

To explore possible environmental drivers of bacterial community structure in the Québec lakes, we examined the correlation between environmental factors and the NMDS ordination of community structure. As was seen in the UPGMA analysis, NMDS revealed that boreal lakes in the north clustered separately from temperate lakes located in the southern part of Québec (Fig. 3). Community structure was significantly correlated with temperature (ADONIS in vegan $\mathrm{R}$ package: $\mathrm{r}^{2}=0.64, \mathrm{p}=0.001$ ), chl a concentration $\left(\mathrm{r}^{2}=0.28, \mathrm{p}=0.003\right), \mathrm{pH}\left(\mathrm{r}^{2}=0.28\right.$, $\mathrm{p}=0.003)$ and the DOC: $\mathrm{chl} a$ ratio $\left(\mathrm{r}^{2}=0.21, \mathrm{p}=\right.$ $0.005)$, as seen by the vectors fitted to the ordination (Fig. 3). While boreal and temperate lakes separated mostly along a $\mathrm{pH}$ and chl a gradient, the seasonal differences in composition were mostly driven by changes in temperature and the DOC:chl a ratio. Even so, there was no indication that the correlation was due to differences in community structure between the temperate and boreal lakes (Fig. 3).

The environmental factors correlating with seasonal shifts in community structure appeared to dif-

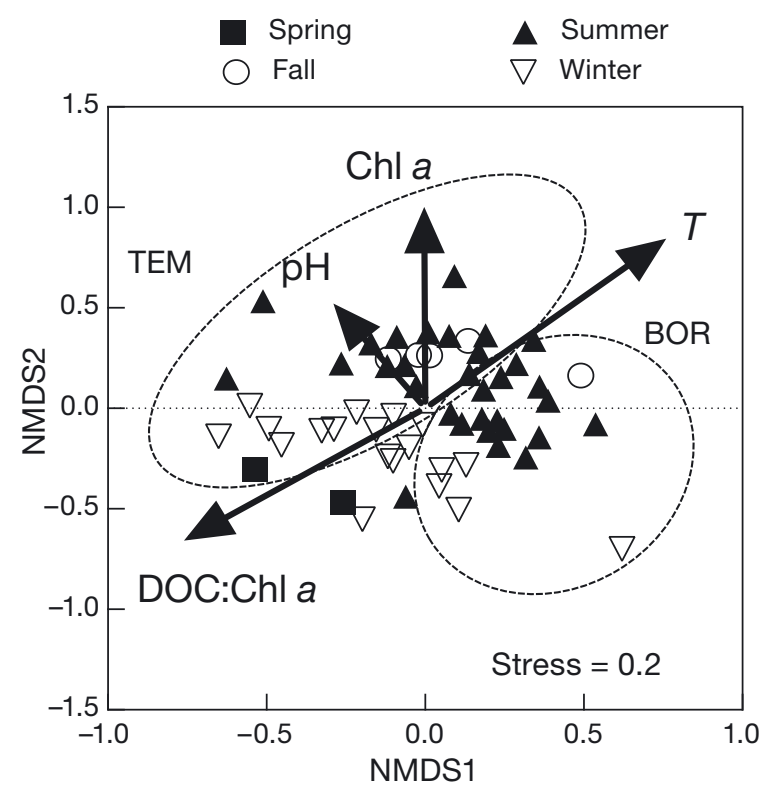

Fig. 3. Non-metric multidimensional scaling (NMDS) ordination of bacterial communities in 57 samples collected from 18 lakes in Québec. The analysis was performed using abundances of OTUs defined at $97 \%$ sequence similarity. The arrows indicate significant correlations $(p<0.05)$ between environmental parameters and community structure. Clusters of temperate (TEM) and boreal (BOR) lakes are Fig. 3 was corrected indicted by the dashed ellipses fer from those separating community structure in temperate versus boreal lakes. The NMDS ordination revealed a clear difference between community structure in summer and winter (Fig. 3), as indicated before in the UPGMA analyses. Spring and fall communities appeared to be distinct from each other, but the fall community structure could not be distinguished from the summer community, and community structure in spring was not distinct from that in winter. The seasonal shift in community structure between summer and winter was consistent with variation in temperature and the DOC:chl a ratio (Fig. 3). Not surprisingly, the vector representing temperature pointed in the direction of the summer community structure. In contrast, the DOC:chl a ratio vector pointed in the direction of community structure in winter. Although the community structure ordination was significantly correlated with $\mathrm{pH}$, there was no obvious relationship between $\mathrm{pH}$ and the seasonal shift in community structure (Fig. 3). Likewise, chl $a$ and the seasonal shift in community structure did not seem to be related.

We also evaluated the impact of various environmental properties on community structure by calculating correlations between those properties and the abundance of bacteria grouped at the phylum or class level. Phylum and class abundances significantly varied with temperature, chl $a$, DOC:chl a ratio, and $\mathrm{pH}$, suggesting that these environmental variables play a role in shaping community structure (Table 2). Alphaproteobacteria, Betaproteobacteria and Cyanobacteria were positively correlated with temperature, with correlation coefficients ranging from $\mathrm{r}=0.33$ for Alphaproteobacteria to $\mathrm{r}=0.46 \mathrm{n}=$ 57) for Proteobacteria. In contrast, Verrucomicrobia were negatively correlated with temperature ( $\mathrm{r}=$ $-0.44, \mathrm{n}=57$ ) (Table 2). The abundance of Verrucomicrobia was correlated negatively with $\mathrm{chl}$ a $(\mathrm{r}=$ $-0.33, \mathrm{p}<0.05, \mathrm{n}=47$ ), suggesting that the abundance of this group does not respond positively to inputs of fresh autochthonous organic materials (Table 2). The abundance of Verrucomicrobia was positively correlated with the DOC:chl a ratio ( $\mathrm{r}=$ $0.36, \mathrm{p}<0.05, \mathrm{n}=46$ ). In contrast, the abundance of Cyanobacteria was negatively correlated with the DOC:chl a ratio ( $\mathrm{r}=-0.35, \mathrm{p}<0.05, \mathrm{n}=46$ ) (Table 2). Partial correlation analyses revealed that the correlation between the abundance of Verrucomicrobia and the DOC:chl a ratio was $r=0.26(p=0.07, n=46)$ after controlling for the influence of $\mathrm{chl} a$. The partial correlation between the abundance of Cyanobacteria and the DOC: $\mathrm{chl}$ a ratio was not significant $(\mathrm{r}=-0.21$, $\mathrm{p}=0.15, \mathrm{n}=46$ ). 
Table 2. Correlations between phylum and class level taxa and environmental variables in the Québec lakes. Chl a: chlorophyll $a_{\text {; }}$ DOC: dissolved organic carbon; $\mathrm{n}$ : number of lake samples; ns: not significant

\begin{tabular}{|c|c|c|c|c|}
\hline Group & Environmental factor & $\mathrm{r}$ & $\mathrm{p}$ & $\mathrm{n}$ \\
\hline Actinobacteria & Temperature & 0.21 & ns & 57 \\
\hline Bacteroidetes & Temperature & -0.12 & ns & 57 \\
\hline Cyanobacteria & Temperature & 0.43 & $<0.05$ & 57 \\
\hline Proteobacteria & Temperature & 0.46 & $<0.05$ & 57 \\
\hline Verrucomicrobia & Temperature & -0.44 & $<0.05$ & 57 \\
\hline Alphaproteobacteria & Temperature & 0.34 & $<0.05$ & 57 \\
\hline Betaproteobacteria & Temperature & 0.42 & $<0.05$ & 57 \\
\hline Actinobacteria & Chl a & -0.01 & ns & 47 \\
\hline Bacteroidetes & Chl a & 0.14 & ns & 47 \\
\hline Cyanobacteria & Chl a & 0.43 & $<0.05$ & 47 \\
\hline Proteobacteria & Chl a & 0.03 & ns & 47 \\
\hline Verrucomicrobia & Chl a & -0.33 & $<0.05$ & 47 \\
\hline Alphaproteobacteria & Chl a & 0.02 & $\mathrm{~ns}$ & 47 \\
\hline Betaproteobacteria & Chl a & 0.03 & ns & 47 \\
\hline Actinobacteria & DOC:chl a ratio & -0.20 & ns & 46 \\
\hline Bacteroidetes & DOC:chl a ratio & 0.03 & ns & 46 \\
\hline Cyanobacteria & DOC:chl a ratio & -0.35 & $<0.05$ & 46 \\
\hline Proteobacteria & DOC:chl a ratio & -0.22 & $\mathrm{~ns}$ & 46 \\
\hline Verrucomicrobia & DOC:chl a ratio & 0.36 & $<0.05$ & 46 \\
\hline Alphaproteobacteria & DOC:chl a ratio & -0.19 & ns & 46 \\
\hline Betaproteobacteria & DOC:chl a ratio & -0.14 & ns & 46 \\
\hline Actinobacteria & $\mathrm{pH}$ & -0.02 & ns & 31 \\
\hline Bacteroidetes & $\mathrm{pH}$ & 0.15 & ns & 31 \\
\hline Cyanobacteria & $\mathrm{pH}$ & 0.01 & ns & 31 \\
\hline Proteobacteria & $\mathrm{pH}$ & 0.16 & ns & 31 \\
\hline Verrucomicrobia & $\mathrm{pH}$ & -0.35 & ns & 31 \\
\hline Alphaproteobacteria & $\mathrm{pH}$ & 0.27 & ns & 31 \\
\hline Betaproteobacteria & $\mathrm{pH}$ & -0.25 & ns & 31 \\
\hline
\end{tabular}

Some environmental factors and taxonomic groups were not significantly correlated. There was no significant correlation between $\mathrm{pH}$ and the abundance of any taxa defined at the phylum or class level (Table 2), which is noteworthy because overall community structure was significantly correlated with $\mathrm{pH}$ (Fig. 3). In addition, there was no correlation between any environmental factor aside from temperature and the abundances of Proteobacteria, Alphaproteobacteria, Betaproteobacteria, Actinobacteria or Bacteroidetes (Table 2).

\section{Common taxa within Québec lakes}

Tag pyrosequences of 16S rRNA genes from all of the sampled Québec lakes could be grouped into 397 OTUs (defined at the $97 \%$ level). Of the 397 OTUs, 18 were seen in 65 to $97 \%$ of the Québec lakes (Table 3). Over 100 of the 397 OTUs were identified as Proteobacteria. In contrast, the most abundant OTUs were members of the Verrucomicrobia, making up 3.4 to $5.4 \%$ of the total community, while OTUs of the Planctomycetes and Proteobacteria made up 1.5 and 0.2 to $0.9 \%$, respectively. Bacteria belonging to the Bacteroidetes appeared to be the most diverse and included 237 OTUs (Table 3), although individually each OTU

Table 3. Common bacterial taxa seen in $>65 \%$ Québec lakes identified by tag pyrosequencing of SSU rRNA genes. \% of lakes: fraction of lakes in which the indicated taxon was found; \% of total community: fraction of total reads attributed by the indicated taxon. OTUs were defined at the $97 \%$ level

\begin{tabular}{|c|c|c|c|c|c|c|c|c|}
\hline Phylum & Class & Order & Family & Genus & $\begin{array}{l}\% \text { of } \\
\text { lakes }\end{array}$ & $\begin{array}{c}\% \text { of total } \\
\text { community }\end{array}$ & $\mathrm{SD}$ & $\begin{array}{l}\text { No. of } \\
\text { OTUs }\end{array}$ \\
\hline Proteobacteria & Betaproteobacteria & Burkholderiales & Burkholderiaceae & betII & 82 & 0.5 & 0.7 & 2 \\
\hline Proteobacteria & Alphaproteobacteria & Caulobacterales & Caulobacteraceae & Caulobacter & 74 & 0.3 & 0.4 & 6 \\
\hline Proteobacteria & Alphaproteobacteria & Rhodospirillales & Rhodospirillaceae & & 71 & 0.2 & 0.4 & 32 \\
\hline Proteobacteria & Betaproteobacteria & Rhodocyclales & & & 71 & 0.5 & 1.0 & 15 \\
\hline Bacteroidetes & Sphingobacteria & Sphingobacteriales & Chitinophagaceae & & 97 & 0.7 & 0.7 & 70 \\
\hline Bacteroidetes & Sphingobacteria & Sphingobacteriales & Flexibacteraceae & & 94 & 0.8 & 0.7 & 74 \\
\hline Bacteroidetes & Flavobacteria & Flavobacteriales & Flavobacteriaceae & Flavobacterium & 74 & 0.7 & 1.2 & 65 \\
\hline Bacteroidetes & Sphingobacteria & Sphingobacteriales & bacI & & 74 & 0.3 & 0.5 & 22 \\
\hline Bacteroidetes & & & & & 76 & 0.4 & 0.7 & 6 \\
\hline Verrucomicrobia & Opitutae & Puniceicoccales & Puniceicoccaceae & & 82 & 5.4 & 7.9 & 6 \\
\hline Chloroflexi & SOGA31 & & & & 85 & 0.5 & 0.5 & 13 \\
\hline
\end{tabular}


accounted for $<1 \%$ of the total community. The Verrucomicrobia, Planctomycetes and Chloroflexi were each represented by 26 or fewer OTUs (Table 3).

\section{Contrasts between Québec lakes and the global lake data set}

Community structure at the phylum and class levels of the Québec lakes was similar to that of the global lake data set compiled by Newton et al. (2011) but differed in the relative contribution of some abundant taxa. Proteobacteria, Actinobacteria and Cyanobacteria accounted for $44 \pm 12,23 \pm 9$ and $4.7 \pm$ $6 \%$, respectively, of the total bacteria in the Québec lakes, about the same as seen in the global data set. However, one notable difference at the phylum level was the 5-fold higher abundance of Verrucomicrobia in the Québec lakes than elsewhere. Verrucomicrobia averaged $14 \pm 11 \%$ of the total bacterial community in the Québec lakes, compared to $3 \%$ in the global lake data set. In contrast, the abundance of Bacteroidetes was 2.5-fold lower in the Québec lakes than the global average $(6.3 \pm 3.5 \%$ vs. $17 \%)$. The remaining phyla accounted for less than $2 \%$ of the bacterial community in the Québec lakes (Fig. S5). Uncertainties in the abundances of these taxa make it difficult to resolve differences between environments, but the data suggest that Firmicutes and Acidobacteria contribute 10 -fold more to the total community in Québec lakes than in the global lake data set. Firmicutes accounted for $2.3 \pm 5.2 \%$ of the total

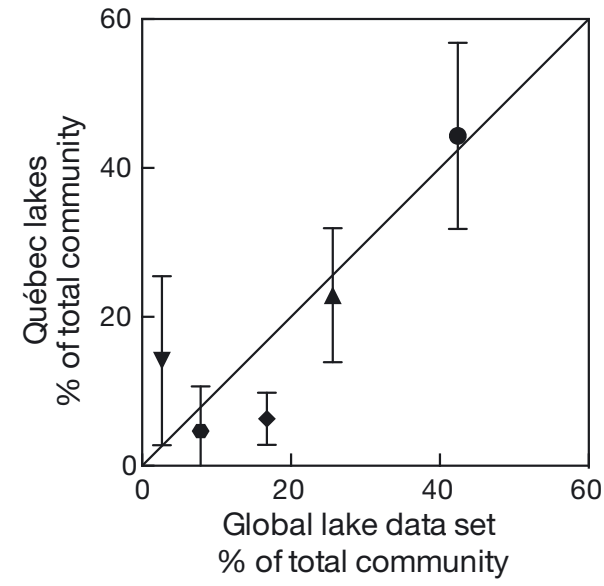

- Proteobacteria - Bacteroidetes $\mathbf{\nabla}$ Verrucomicrobia

Fig. 4. Relative abundance of bacterial classes in all Québec lakes versus the global lake data set (Newton et al. 2011). Diagonal line represents a 1:1 relationship. Errors bars (SD) reflect the variation among the lakes in Québec bacterial community in the Québec lakes compared to $0.14 \%$ of the total lake data set. Similarly, Acidobacteria averaged $0.23 \pm 0.54 \%$ of Québec lake bacteria but only $0.08 \%$ of bacteria in the global lake data set (Fig. S5)

Differences between the Québec lakes and the global data set were apparent at the class level as well. The relative contribution of Alphaproteobacteria was 2-fold higher in the Québec lakes than in the global data set. On average, Alphaproteobacteria accounted for $22 \pm 14 \%$ of the bacteria seen in the Québec lakes, but overall Alphaproteobacteria accounted for only $9 \%$ of the OTUs in the global data set (Fig. 4). Similarly, members of the Opitutae, a class in the Verrucomicrobia, were 15 -fold more abundant in the Québec lakes than have been reported elsewhere $(13 \pm 11 \%$ vs. $0.8 \%)$. Bacteria in other groups typically accounted for $1 \%$ or less of the bacteria in the global data set.

\section{Globally common tribes of freshwater lake bacteria}

Our analyses revealed that Québec lakes had 67 of the 79 tribes identified by Newton et al. (2011) as forming the core of bacterial communities in freshwater lakes. On average each of the 79 tribes of freshwater lake bacteria was found in $30 \%$ of the lakes we examined (Fig. 5A) compared with $20 \%$ of lakes sampled globally (Newton et al. 2011) (Fig. 5B). The prevalence of most of these taxa in Québec lakes paralleled that in the global data set, as there was a significant correlation between the fraction of lakes with a tribe and the analogous fraction in the global data set $(r=0.45, p<0.05, n=79)$. However, 12 of the 79 common freshwater bacteria were not seen in any of the Québec lakes. For example, the Cyth, IlumaA1 and acI-B4 tribes were seen in 30 to $51 \%$ of lakes outside of Québec but were not detected in this study (Fig. 5). Similarly, several tribes were very common in the Québec lakes but much less so in lakes elsewhere. For example, bacI-B1 was observed in $100 \%$ of the Québec lakes, but was present in only $2 \%$ of lakes sampled globally. The Xip-A1 and Rhodo tribes were identified in 98 and $96 \%$ of the Québec lakes, respectively, but in fewer than $20 \%$ of lakes located elsewhere (Fig. 5).

Although a large fraction of bacterial tribes in the global set were found in the Québec lakes, the relative contributions of these taxa differed. The contributions of the common bacterial tribes identified to the global data set were significantly correlated with their relative abundances in the Québec lakes $(r=0.58$, 

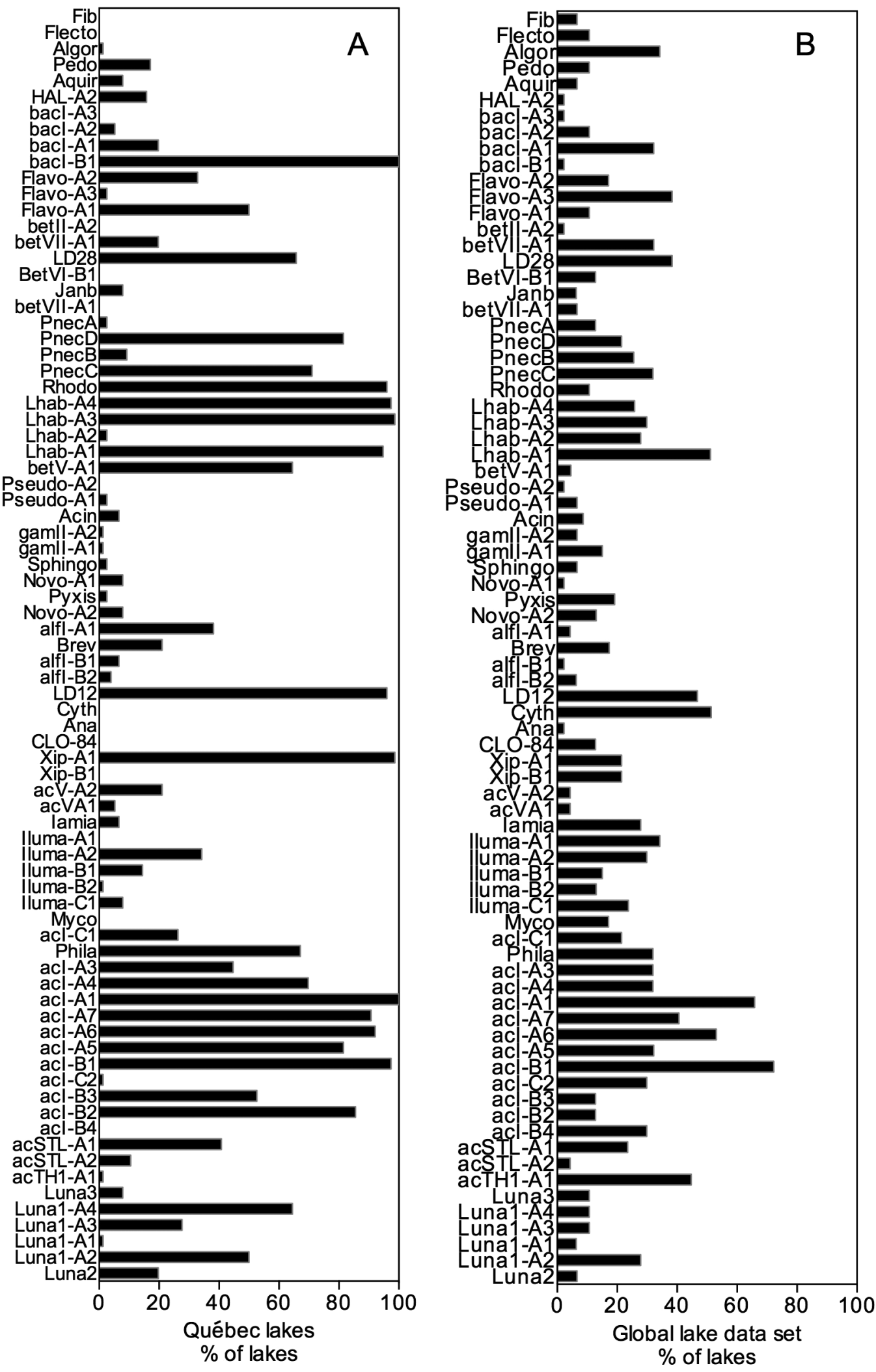

Fig. 5. Prevalence of freshwater lake bacterial tribes (Newton et al. 2011) in (A) Québec lakes and (B) the global lake data set. Prevalence is the percentage of the 57 lake samples in which a tag sequence was detected. Prevalence in the global lake data set was reported by Newton et al. (2011) 
$\mathrm{p}<0.05, \mathrm{n}=79$ ). However, overall these common bacteria were only half as prevalent in the Québec lakes, where they averaged $0.7 \%$ of the total community compared to $1.3 \%$ of the total community in the global data set (paired $t$-test: $\mathrm{p}<0.05, \mathrm{n}=79$ ) (Fig. 6). In the global lake data set, the most abundant bacteria, which belonged to the Lhab-A1 tribe, were 10-fold more abundant than in the Québec lakes. The LhabA1 tribe accounted for 9 and $0.7 \pm 0.9 \%$ of the bacteria in the global community and Québec lake communities, respectively (Fig. 6B). Likewise, many of the most abundant tribes in the Québec lakes were much less abundant in the global lake data set. The most abundant bacterial tribe seen in our study belonged to the SAR11-related LD12 group, accounting for $17 \pm 14 \%$ of the total community in the Québec lakes. In the global lake data set, LD12 ranked seventh, averaging $4 \%$ of the bacteria (Fig. 6A).

\section{DISCUSSION}

We hypothesized that community structure of bacteria in boreal and temperate lakes of Québec would differ because of the distinct environmental conditions in these 2 regions. Our results revealed clear differences in the bacterial communities of lakes distributed over approximately $7^{\circ}$ of latitude (approximately $1200 \mathrm{~km}$ ) in summer and winter. Differences in bacterial community structure did correlate with geographic distance between lakes, indicating that at this spatial scale, the biogeography of temperate and boreal lakes in Québec appears to follow the distance-decay relationship found by previous studies (Horner-Devine et al. 2004, Hewson et al. 2006, Soininen et al. 2011, Jones et al. 2012). However, our results also show that differences in community structure among the Québec lakes were dominated by environmental factors.

The significant effect of environmental factors is consistent with the mounting evidence that environmental selection is one of the main drivers of bacterial biogeography (Hanson et al. 2012). Other factors that may contribute to the biogeography of bacteria include drift, dispersal and mutation (Sul et al. 2013, Hellweger et al. 2014). In our study of Québec lakes, the effect of geographic distance was very small compared to that of environmental selection, suggesting that the impacts of drift and dispersal are small. In other regions of Québec where impacts of geographic distance may be more prominent, Ruiz-González et al. (2015a) demonstrated that bacterial communities have a directional spatial structure driven by a com- mon terrestrial origin of aquatic communities. However, only about $50 \%$ of the variation in community structure could be explained by the environmental factors measured in this study. Including additional environmental factors is an obvious way to explain an even larger fraction of the biogeographical variation in these lakes. Top-down effects of grazers and viruses have not been considered in models of biogeography (Hanson et al. 2012). Perhaps the effects are not great in lakes, since the correlations between bacterial and viral communities in the lakes examined so far appear to be weak and indirect (Lymer et al. 2008). Regardless, more data are needed to rule out the impacts of such top-down effects on bacterial biogeography in freshwater lakes and elsewhere.

One of our expectations was that factors related to the composition of the dissolved organic matter (DOM) would explain differences in community structure between the boreal and temperate lakes we examined. Previous work indicated that DOC concentration or quality has an impact on bacterial community structure (Yannarell \& Triplett 2004, 2005, Jones et al. 2009). In other regions of Québec, the functional biogeography of boreal bacterioplankton appears to be driven by the nature of the DOM pool, and particularly by the influence of terrestrial DOM (Ruiz-González et al. 2015b). In temperate lakes of Wisconsin, USA, Jones et al. (2009) identified many bacterial taxa whose occurrence correlated with the terrestrial versus phytoplankton source of carbon substrates. However, differences in community structure between the temperate and boreal lakes appeared to be related to chl a concentration and $\mathrm{pH}$, not DOC concentrations or the DOC:chl a ratio. We suspect that no relationship was seen for these factors because total DOC concentration and the DOC:chl a ratio are poor proxies for the actual substrates being consumed by bacteria.

We expected alpha diversity to be higher in winter than in summer because studies in high-latitude freshwaters and marine systems and mid-latitude coastal oceans consistently reveal higher alpha diversity in winter than in summer (Crump et al. 2009, Caporaso et al. 2012, Ghiglione \& Murray 2012). In contrast, we did not find any significant difference in alpha diversity between summer and winter in the Québec lakes. Unlike the systems where alpha diversity has been shown to vary with the seasons, the Québec lakes tend to be small and ice-covered in winter. However, diversity varied between spring and fall in one small lake, Lake Mendota, Wisconsin, which is also ice-covered in winter (Shade et al. 2007). More work is needed to determine if the sea- 

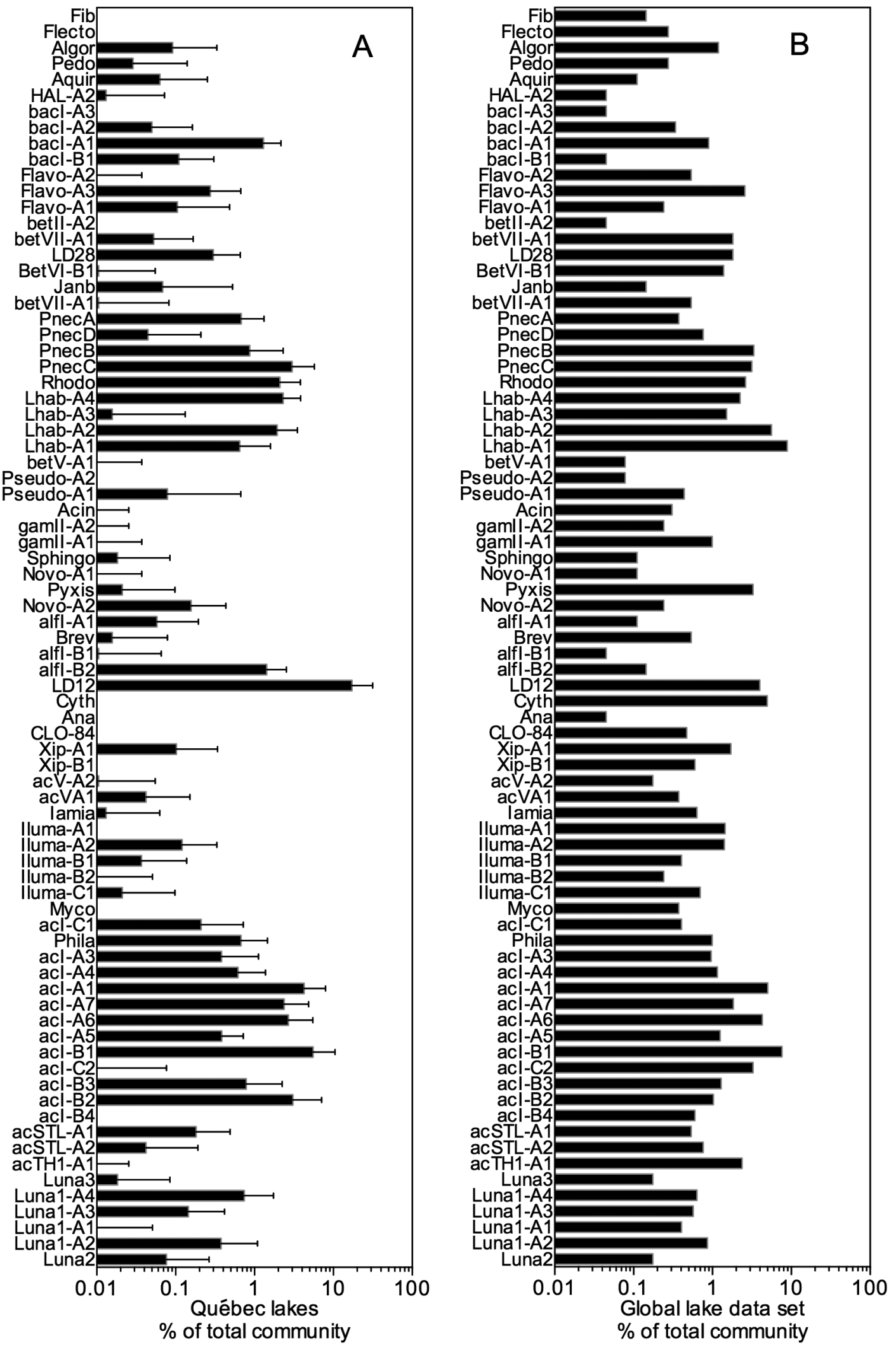

Fig. 6. Abundance of freshwater lake bacteria (Newton et al. 2011) in (A) Québec lakes and (B) the global lake data set. Abundance in the Québec lakes was calculated by dividing the number of times a tag sequence was seen by the total number of tag sequences obtained from 57 lake samples. Abundance in the global lake data set was reported by Newton et al. (2011) 
sonal change in alpha diversity differs between icecovered lakes and other aquatic systems.

The overall taxonomic composition of bacterial communities of the temperate and boreal lakes of Québec was similar to that in the global data set. Essentially all of the common bacterial taxa seen globally (Newton et al. 2011) were identified in the Québec lakes. It is unclear if even deeper sequencing would have revealed the few common taxa seen in the global data set (Newton et al. 2011) that were not detected in the Québec lakes. Much smaller data sets from temperate and tropical ecosystems also provided hints that freshwater lakes include a core set of common taxa (Humbert et al. 2009). Other studies from circumpolar freshwaters indicated that the same common bacterial taxa can be identified throughout the pan-Arctic region (Crump et al. 2009). Along with those previous studies, our results suggest that freshwater lakes contain many of the globally common taxa regardless of geographic location, probably because biogeochemical properties are similar enough among all lakes to select for bacterial communities that share the core dominant taxa.

Although many of the globally common taxa were present in the Québec lakes, abundances differed from the global data set. The difference was not attributable to one region in Québec alone, as the temperate and boreal data sets each differed from the global lake data set. This global data set is based on sequences from a large number of lakes in northern Europe and North America, with some data from Asia and Africa, suggesting that geographical variation in abundances may be partly responsible for the difference between our data and the global data set. Undetermined environmental differences between Québec lakes and elsewhere potentially play a role as well, so additional environmental data will be needed to test this possibility. In addition, the methodological approaches may also be part of the explanation. In this study, bacterial biomass was collected from water pre-filtered through a $1 \mu \mathrm{m}$ pore size filter. In contrast, a pre-filtration step was used in only half of the studies compiled by Newton et al. (2011). The filtration step removes particles and could selectively remove bacterial taxa such as Bacteroidetes that are often found to be in greater abundance on particles than in the free-living community (Allgaier \& Grossart 2006). In addition, the global data set consists entirely of sequences obtained from traditional approaches, not from next-generation sequencing tools. Analyses of freshwater bacterial communities using next-generation sequencing are now becoming available, and have revealed aspects of taxonomic richness and association networks of OTUs (Eiler et al. 2012, Logue et al. 2012). Our study and any other work relying on 16S rRNA genes alone are subject to the strengths and weaknesses associated with this approach (Poretsky et al. 2014).

Next-generation sequencing is also beginning to reveal the dynamics of bacterial community structure in boreal lakes and other high-latitude environments. One such study of lakes in the boreal forests of Finland found distinct and diverse anaerobic bacterial communities dominated by members of the OD1 candidate division (Peura et al. 2012). The $5 \mathrm{yr}$ time series study demonstrated that hypolimnetic bacterial communities are less dynamic but more taxonomically diverse than communities in the oxic surface layer (Peura et al. 2012). In contrast to our study, which focused on surface waters of boreal lakes in Québec, the Finish lake study examined waters in the epilimnion and hypliminon and showed that representation of taxa previously described as typical for freshwater (Newton et al. 2011) was low in the deeper, anoxic waters.

Shifts in community structure of freshwater bacteria in temperate lakes have been seen to reflect largescale variation in climate (Magnuson et al. 2005, Shade et al. 2007). Climate change impacts are already altering the boreal and temperate zone landscape (Lafleur et al. 2010), with consequences on the loading of carbon and nutrients to lakes (Lapierre et al. 2015), and we expect that bacterial communities in Québec lakes may shift as a result. Concentrations of DOC in boreal and temperate lakes of Québec increased at a rate of $0.05 \mathrm{mg} \mathrm{l}^{-1} \mathrm{yr}^{-1}$ from 1996 to 2006 (Couture et al. 2012). In addition, local warming of the boreal-temperate ecotone in eastern North America has already shortened the duration of ice cover of lakes by up to $21 \mathrm{~d}$ (Beier et al. 2012), potentially altering seasonal shifts in bacterial community structure through cascading effects on phytoplankton productivity and production of organic materials supporting bacterial growth (Beier et al. 2012). Establishing a baseline of lake bacterial community structure and biogeography in the boreal and temperate lakes of Québec will facilitate future exploration of potential responses of these communities to changing climate.

Acknowledgements. We thank Lisa Fauteux and Juan Pablo Niño for help with sample collection and processing, and Clara Ruiz-Gonzalez for critical comments on the manuscript. The work was supported by U.S. National Science Foundation (NSF) grant DEB0814918 and is part of the Carbon Biogeochemistry in Boreal Aquatic Ecosystems (CarBBAS) research program, jointly funded by the National Science and Engineering Research Council of Canada and Hydro-Québec. 


\section{LITERATURE CITED}

Allgaier M, Grossart HP (2006) Seasonal dynamics and phylogenetic diversity of free-living and particle-associated bacterial communities in four lakes in northeastern Germany. Aquat Microb Ecol 45:115-128

Altschul SF, Gish W, Miller W, Myers EW, Lipman DJ (1990) Basic local alignment search tool. J Mol Biol 215:403-410

- Barberán A, Casamayor EO (2010) Global phylogenetic community structure and beta-diversity patterns in surface bacterioplankton metacommunities. Aquat Microb Ecol 59:1-10

> Beier CM, Stella JC, Dovciak M, McNulty SA (2012) Local climatic drivers of changes in phenology at a borealtemperate ecotone in eastern North America. Clim Chang 115:399-417

Benoy G, Cash K, McCauley E, Wrona F (2007) Carbon dynamics in lakes of the boreal forest under a changing climate. Environ Rev 15:175-189

> Buffam I, Turner MG, Desai AR, Hanson PC and others (2011) Integrating aquatic and terrestrial components to construct a complete carbon budget for a north temperate lake district. Glob Change Biol 17:1193-1211

Caporaso JG, Kuczynski J, Stombaugh J, Bittinger K and others (2010) Qiime allows analysis of high-throughput community sequencing data. Nat Methods 7:335-336

Caporaso JG, Paszkiewicz K, Field D, Knight R, Gilbert JA (2012) The western English Channel contains a persistent microbial seed bank. ISME J 6:1089-1093

Chase JM, Myers JA (2011) Disentangling the importance of ecological niches from stochastic processes across scales. Philos Trans R Soc Lond B 366:2351-2363

> Couture S, Houle D, Gagnon C (2012) Increases of dissolved organic carbon in temperate and boreal lakes in Quebec, Canada. Environ Sci Pollut R 19:361-371

> Crump BC, Adams HE, Hobbie JE, Kling GW (2007) Biogeography of bacterioplankton in lakes and streams of an Arctic tundra catchment. Ecology 88:1365-1378

Crump BC, Peterson BJ, Raymond PA, Amon RMW, Rinehart A, McClelland JW, Holmes RM (2009) Circumpolar synchrony in big river bacterioplankton. Proc Natl Acad Sci USA 106:21208-21212

> Crump BC, Amaral-Zettler LA, Kling GW (2012) Microbial diversity in Arctic freshwaters is structured by inoculation of microbes from soils. ISME J 6:1629-1639

> Dempster EL, Pryor KV, Francis D, Young JE, Rogers HJ (1999) Rapid DNA extraction from ferns for PCR-based analyses. Biotechniques 27:66-68

DeSantis TZ, Hugenholtz P, Larsen N, Rojas M and others (2006) Greengenes, a chimera-checked 16S rRNA gene database and workbench compatible with ARB. Appl Environ Microbiol 72:5069-5072

Edgar RC (2010) Search and clustering orders of magnitude faster than blast. Bioinformatics 26:2460-2461

Eiler A, Heinrich F, Bertilsson S (2012) Coherent dynamics and association networks among lake bacterioplankton taxa. ISME J 6:330-342

Fuhrman JA, Steele JA, Hewson I, Schwalbach MS, Brown MV, Green JL, Brown JH (2008) A latitudinal diversity gradient in planktonic marine bacteria. Proc Natl Acad Sci USA 105:7774-7778

Ghiglione JF, Murray AE (2012) Pronounced summer to winter differences and higher wintertime richness in coastal Antarctic marine bacterioplankton. Environ Microbiol 14:617-629
Glöckner FO, Fuchs BM, Amann R (1999) Bacterioplankton compositions of lakes and oceans: a first comparison based on fluorescence in situ hybridization. Appl Environ Microbiol 65:3721-3726

> Haas BJ, Gevers D, Earl AM, Feldgarden M and others (2011) Chimeric 16S rRNA sequence formation and detection in Sanger and 454-pyrosequenced PCR amplicons. Genome Res 21:494-504

Hamady M, Walker JJ, Harris JK, Gold NJ, Knight R (2008) Error-correcting barcoded primers for pyrosequencing hundreds of samples in multiplex. Nat Methods 5: 235-237

Hanson CA, Fuhrman JA, Horner-Devine MC, Martiny JBH (2012) Beyond biogeographic patterns: processes shaping the microbial landscape. Nat Rev Microbiol 10: 497-506

Hellweger FL, van Sebille E, Fredrick ND (2014) Biogeographic patterns in ocean microbes emerge in a neutral agent-based model. Science 345:1346-1349

> Hewson I, Steele JA, Capone DG, Fuhrman JA (2006) Temporal and spatial scales of variation in bacterioplankton assemblages of oligotrophic surface waters. Mar Ecol Prog Ser 311:67-77

Horner-Devine MC, Lage M, Hughes JB, Bohannan BJM (2004) A taxa-area relationship for bacteria. Nature 432: $750-753$

Humbert JF, Dorigo U, Cecchi P, Le Berre B, Debroas D, Bouvy M (2009) Comparison of the structure and composition of bacterial communities from temperate and tropical freshwater ecosystems. Environ Microbiol 11: 2339-2350

İnceoğlu Ö, Llirós M, Crowe S, García-Armisen T and others (2015) Vertical distribution of functional potential and active microbial communities in meromictic Lake Kivu. Microb Ecol 70:596-611

Jones SE, Newton RJ, McMahon KD (2009) Evidence for structuring of bacterial community composition by organic carbon source in temperate lakes. Environ Microbiol 11:2463-2472

Jones SE, Cadkin TA, Newton RJ, McMahon KD (2012) Spatial and temporal scales of aquatic bacterial beta diversity. Front Microbiol 3:1-10

> Jost L (2007) Partitioning diversity into independent alpha and beta components. Ecology 88:2427-2439

> Kan J, Wang K, Chen F (2006) Temporal variation and detection limit of an estuarine bacterioplankton community analyzed by denaturing gradient gel electrophoresis (DGGE). Aquat Microb Ecol 42:7-18

Kaplan LA (1992) Comparison of high-temperature and persulfate oxidation methods for determination of dissolved organic carbon in freshwaters. Limnol Oceanogr 37: 1119-1125

Kulichevskaya IS, Belova SE, Komov VT, Dedysh SN, Zavarzin GA (2011) Phylogenetic composition of bacterial communities in small boreal lakes and ombrotrophic bogs of the upper Volga basin. Microbiology 80: 549-557

Lafleur B, Pare D, Munson AD, Bergeron Y (2010) Response of northeastern North American forests to climate change: will soil conditions constrain tree species migration? Environ Rev 18:279-289

Lapierre JF, Seekell DA, del Giorgio PA (2015) Climate and landscape influence on indicators of lake carbon cycling through spatial patterns in dissolved organic carbon. Glob Change Biol (in press) 
Lee CK, Herbold CW, Polson SW, Wommack KE, Williamson SJ, McDonald IR, Cary SC (2012) Groundtruthing nextgen sequencing for microbial ecology-biases and errors in community structure estimates from PCR amplicon pyrosequencing. PLoS ONE 7:e44224, doi:10.1371/ journal.pone.0044224

Lindstrom ES, Forslund M, Algesten G, Bergstrom AK (2006) External control of bacterial community structure in lakes. Limnol Oceanogr 51:339-342

Logares R, Lindstrom ES, Langenheder S, Logue JB and others (2013) Biogeography of bacterial communities exposed to progressive long-term environmental change. ISME J 7:937-948

Logue JB, Lindström ES (2008) Biogeography of bacterioplankton in inland waters. Freshw Rev 1:99-114

Logue JB, Langenheder S, Andersson AF, Bertilsson S, Drakare S, Lanzen A, Lindstrom ES (2012) Freshwater bacterioplankton richness in oligotrophic lakes depends on nutrient availability rather than on species-area relationships. ISME J 6:1127-1136

Ludwig W, Strunk O, Westram R, Richter L and others (2004) ARB: a software environment for sequence data. Nucleic Acids Res 32:1363-1371

Lymer D, Logue JB, Brussaard CPD, Baudoux AC, Vrede K, Lindstrom ES (2008) Temporal variation in freshwater viral and bacterial community composition. Freshw Biol 53:1163-1175

Magnuson JJ, Kratz TK, Benson BJ (2005) Long-term dynamics of lakes in the landscape. Oxford University Press, Oxford

Newton RJ, Jones SE, Eiler A, McMahon KD, Bertilsson S (2011) A guide to the natural history of freshwater lake bacteria. Microbiol Mol Biol R 75:14-49

Oksanen J, Blanchet G, Kindt R, Legendre P and others (2015) Vegan: community ecology package. R package version 2.3-0. http://CRAN.R-project.org/package=vegan

Peura S, Eiler A, Bertilsson S, Nykanen H, Tiirola M, Jones RI (2012) Distinct and diverse anaerobic bacterial communities in boreal lakes dominated by candidate division OD1. ISME J 6:1640-1652

Peura S, Bertilsson S, Jones RI, Eiler A (2015) Resistant microbial cooccurrence patterns inferred by network topology. Appl Environ Microbiol 81:2090-2097

Pommier T, Canback B, Riemann L, Bostrom KH and others (2007) Global patterns of diversity and community structure in marine bacterioplankton. Mol Ecol 16:867-880

Pontarp M, Canbäck B, Tunlid A, Lundberg P (2012) Phylogenetic analysis suggests that habitat filtering is structuring marine bacterial communities across the globe. Microb Ecol 64:8-17

> Poretsky R, Rodriguez-R LM, Luo CW, Tsementzi D, Konstantinidis KT (2014) Strengths and limitations of $16 \mathrm{~S}$ rRNA gene amplicon sequencing in revealing temporal microbial community dynamics. PLoS ONE 9:e93827

Prairie YT, Bird DF, Cole JJ (2002) The summer metabolic balance in the epilimnion of southeastern Quebec lakes. Limnol Oceanogr 47:316-321

Quince C, Lanzen A, Davenport RJ, Turnbaugh PJ (2011)

Editorial responsibility: Karel Šimek,

České Budějovice, Czech Republic
Removing noise from pyrosequenced amplicons. BMC Bioinformatics 12:38

Reche I, Pulido-Villena E, Morales-Baquero R, Casamayor EO (2005) Does ecosystem size determine aquatic bacterial richness? Ecology 86:1715-1722

Reeder J, Knight R (2010) Rapidly denoising pyrosequencing amplicon reads by exploiting rank-abundance distributions. Nat Methods 7:668-669

> Ruiz-González C, Niño-García JP, del Giorgio PA (2015a) Terrestrial origin of bacterial communities in complex boreal freshwater networks. Ecol Lett 18:1198-1206

> Ruiz-González C, Niño-García JP, Lapierre J-F, del Giorgio PA (2015b) The quality of organic matter shapes the functional biogeography of bacterioplankton across boreal freshwater ecosystems. Glob Ecol Biogeogr (in press)

Sarmento H (2012) New paradigms in tropical limnology: the importance of the microbial food web. Hydrobiologia 686:1-14

Schiaffino MR, Unrein F, Gasol JM, Massana R, Balague V, Izaguirre I (2011) Bacterial community structure in a latitudinal gradient of lakes: the roles of spatial versus environmental factors. Freshw Biol 56:1973-1991

> Shade A, Kent AD, Jones SE, Newton RJ, Triplett EW, McMahon KD (2007) Interannual dynamics and phenology of bacterial communities in a eutrophic lake. Limnol Oceanogr 52:487-494

- Sogin ML, Morrison HG, Huber JA, Welch DM and others (2006) Microbial diversity in the deep sea and the underexplored "rare biosphere". Proc Natl Acad Sci USA 103: 12115-12120

Soininen J, Korhonen JJ, Karhu J, Vetterli A (2011) Disentangling the spatial patterns in community composition of prokaryotic and eukaryotic lake plankton. Limnol Oceanogr 56:508-520

Strickland JDH, Parsons TR (1968) A practical handbook of seawater analysis, Vol. 167 Queen's Printer, Ottawa

Sul WJ, Oliver TA, Ducklow HW, Amaral-Zettler LA, Sogin ML (2013) Marine bacteria exhibit a bipolar distribution. Proc Natl Acad Sci USA 110:2342-2347

> Suzumura M (2008) Persulfate chemical wet oxidation method for the determination of particulate phosphorus in comparison with a high-temperature dry combustion method. Limnol Oceanogr Methods 6:619-629

Werner JJ, Koren O, Hugenholtz P, DeSantis TZ and others (2012) Impact of training sets on classification of highthroughput bacterial 16S rRNA gene surveys. ISME J 6: 94-103

- Woo MK, Thorne R, Szeto K, Yang DQ (2008) Streamflow hydrology in the boreal region under the influences of climate and human interference. Philos Trans R Soc Lond B 363:2251-2260

Yannarell AC, Triplett EW (2004) Within- and between-lake variability in the composition of bacterioplankton communities: investigations using multiple spatial scales. Appl Environ Microbiol 70:214-223

> Yannarell AC, Triplett EW (2005) Geographic and environmental sources of variation in lake bacterial community composition. Appl Environ Microbiol 71:227-239

Submitted: April 29, 2015; Accepted: October 5, 2015

Proofs received from author(s): November 19, 2015 